\title{
Hula Hoop Dance in Early Childhood (Case Study in Bon Thorif Kindergarten, Palembang South Sumatera)
}

\author{
Sri Sumarni, Windi Dwi Andika \\ Sriwijaya University, Indonesia \\ Corresponding e-mail: yik59unsri@yahoo.co.id
}

\begin{abstract}
Digital world nowadays gives positive impact on many aspects of development. However, there are also negative impacts in the shift of activity patterns, from motoric activities to playing gadget in the early childhood, even though it is the golden age of the motor development. This important issue encourages this present study to investigate an appropriate exercise program for early childhood compared to gadget. Based on the preliminary study on the use of Hula Hoop Dance in Bon Thorif kindergarten in Palembang, it was found that this dance is a favored development program to actively engage children to have ideal body proportions. This uniqueness directs the need of conducting a case study on how this dance really matters. There were sixteen children as the research subject. The data were collected by using observation, interview and documentation. By Spradley Model analysis, it was revealed that the psychomotor aspect developed healthy-fitness and children's awareness perception. In the aspect of healthy-fitness, Hula Hoop Dance consists of: balance, coordination, speed, agility, power, innovation, and proportional weight. While in the aspect of awareness perception, Hula Hoop dance consists of: body awareness, spatial awareness, directional awareness, and temporal awareness. Therefore, Hula Hoop Dance is a fun activity which optimizes psychomotoric aspects of development rather than playing gadget. It can also be an alternative development program for early childhood movement throughout the country.
\end{abstract}

Keywords: Hula Hoop dance, early childhood, physical development

\section{INTRODUCTION}

The importance of developing a combination of fundamental movements skill for children aged 5 to 6 years to do is contrary to the phenomena occurring in society in modern times. Phenomena such as the number of children who are lazy to move because of a shift in the pattern of activity of physical activity in outdoor games to computer game/gadget addiction affects the motor skills computer games so that children do not develop optimally.

Gallahue (2003:52) argues that the fundamental movement skills of early childhood development are the result of the rudimentary movement in the infant phase. The fundamental movement skills is divided into three classifications, they are: (1) Locomotor, (2) Manipulative, and (3) Stability Movement Skill. Three movements skill becomes the target motor aspects of the development of preschool children. Fundamental movements phase is a great time to find a way to do range of movements that certainly related to the stability of the balance of the movement. Locomotor movement skill which makes the body to change position, and manipulative movement skill associated with the movement when manipulating objects. Goodway research (2006:2) only combines two fundamental movement skills categories namely: locomotor and manipulative. Anderson and Bourke (2000:4) The fundamental movement skills are skills that a series of movements organized by using two or more parts of the body. Two parts of the body or more means that the combination of the movement of two or more of the child's body parts.

Lemos, et al (2012:17) Physical Development programmatically as a means to channel the excess energy in the child are evident on development in kindergarten. Permendiknas (2009:8) All of coordination, flexibility, balance, and agility of children is closely related to the child's growth and movement control. In addition, factors of health and fitness of children is very influential in this regard. 
For the above matters need to be considered in the provision of physical stimulation and movement in children, physical development and movement in order to develop optimally.

Observations made to some of kindergarten, researchers found distinctiveness interest in Bon Thorif Kindergarten. Bon Thorif Kindergarten able to develop fundamental movement skills of children with a combination of a unique activity is Hula Hoop Dance. There are a variety of unique contained in Hula Hoop Dance in the development of fundamental movement skills in kindergarten combination include: (1) Based on an interview with the principal, activities Hula Hoop Dance is a program of realization of the vision and mission of the Kindergarten Bon Thorif. Hula Hoop Dance serve as a program for optimization of development of psychomotor aspect of children, (2) Based on interviews with teachers, Dancing Hula Hoop done intensely every day, so the development of psychomotor aspect child can develop optimally, (3) Based on interviews with parents, many benefits from Dance Hula Hoop made his balanced body proportions and move on so as to make children less interested in playing video games and the like.

Many researches have described the advantages of playing Hula Hoop. Sarachco (2013:64) states that "Dance is a rhythmic movement". Furthermore Astono, et al (2007:9) states that "the medium of dance is a movement that has the aesthetic element in it". Observing the opinion Sudarsono (1992:39) on top of that feeling you get inside someone would make such a person to take action (action). The action is shown in the form of a movement that has an element of aesthetics, good slow movement to fast. All movements are performed in accordance with the rhythm of the music that accompanies the dance.

The Council on Physical Education for Children (COPEC) in the National Association Sport and Physical Education (NASPE) (2013:4) on before doing the hula hoop dance with the identification of existing physical environment and plaything. In addition NASPE (2013:6) and Wolf (2013:5) suggest should develop locomotor and manipulative movement abilities to use tools, one of which is the Hula Hoop is ideally made of plastic with a diameter of 30 inches and 36 inches. Standard provision in one class Hula Hoop ideally 20 for one class for each child. In addition the ideal equipment that will support the activities of dancing include: $\mathrm{CD} / \mathrm{Music}$ Player, cordless microphone that allows teachers to move while providing intervention, and loudspeakers. Pica (2000:157) also recommends the use of a flat Hula Hoop is considered ideal and most versatile, offering the best possibilities to be manipulated and support other activities.

Numerous literature and research results have become references in viewing the relationship between the Fundamental Movement Skills and Hula Hoop Dance. Pica (2000:70) states that there are four senses in giving developing movement for a child with a Hula Hoop, among others: (1)

Movement, (2) Movements are process oriented towards success, (3) Exploration of movement is a process that leads to discovery, (4) Movement is a powerful tool that integrating various aspects of psychomotor development.

Furthermore Pica (2000:157-158) argues Exploration conducted involving three fundamental movements such as: Locomotor, manipulative, and stability movement skills when the child interacts with the Hula Hoop. There are many possible moves using Hula Hoop. Hula Hoop can be rotated, rolled, swayed, jumped over (such as straps), circling around the body or parts of the body, thrown and caught, lifted, and crawl through (when held upright by a person or Styrofoam holder Hula Hoop).

NASPE (2013:16) state encourages children to put some parts of the body inside the circle and another part outside. Research Lloyd et al (2011:2) which states that the Hula Hoop can be used in the classroom as an activity of non-competitive to promote the relationship between the physical education curriculum and the concept of stability, locomotor, and manipulative movements skill, body awareness and space, and the general principles of the movement. It aims to promote a fun activity in a move to combat behavior once inactivity.

This has attracted researchers to know more about the form of the development of the psychomotor aspect of what can be developed with Hula Hoop Dance performed in kindergarten.

\section{METHODS}

This research used a qualitative method with case study approach, where researchers focused with some restrictions on searches to find the deep meaning of the forms of psychomotor development of the activity of Hula Hoop Dance.

Woodside (2010:1) a case study is an investigation process that focuses on describing, understanding, predicting, and controlling individual. Creswell (2007: 73) examined by describing the parts corresponding to focus and limit the items that are used so that it can reveal about other forms of development of the Hula Hoop Dance 
activities that include psychomotor development in children in group B in kindergarten Bon Thorif.

This study was conducted over 6 months of the second semester of academic year 2013/2014 and kindergarten located in Bon Thorif which is located at Jalan Angkatan 66 Lrg. Harapan V Kecamatan Kemuning, Palembang, South Sumatra. According Moleong opinion (2005:86) site selection researchers adjusted for ease of access. Source of data obtained from children in group B and kindergarten teacher at Bon Thorif, including in this case the parents. As for the teachers who teach in kindergarten Bon Thorif as many as six people and all of $\mathrm{S} 1$ educational background. Children in group B only one class numbering 16 children.

The data collection aims to take its meaning Miles and Huberman (1984:10). Method of observation, documentation, and interviews were used in this study, and analysed using flow models "gradually advanced research Flow" (Development Research Sequence) from Spradley (1980:52). Spradley (1980:103) states that the stages of this research are (1) Selecting a social situation, (2) Doing participant observation, (3) Making a record, (4) making descriptive observations, (5) Making domain analysis, (6) Making focus observations, (7) Making taxonomy analysis, (8) Making selective observation, (9) Making componential analysis, and (10) Making a theme analysis.

\section{RESULT}

The findings of this research are that there are forms of psychomotor development of children which includes two aspects: (1) Health \& fitness, and (2) Awareness perception. Development form of combination of fundamental movement skills at Bon Thorif kindergarten is developed every time children dance Hula Hoop, and was observed to be interpreted based on the record in the form of video documentation.

Health and fitness aspects include: (1) The balance of child's body looks when children keep their static balance and dynamic when performing Hula Hoop dance movements. (2) Coordination is seen when a child coordinate eye-hand movements, eye-foot, and the body in dancing the Hula Hoop. The fundamental movement skill are seen in coordination aspects. (3) Speed is seen when playing Hula Hoop in hand and in the abdomen with a different tempo and appropriate rhythm. (4) Agility is seen when children play Hula Hoop at the hands alternately and play Hula Hoop in the stomach while doing variations of hand or foot movement or body accurately. (5) Power is visible when the child is able to dance Hula Hoop without complaining, always ask for an extra session to dance, and wanted to continue to play the Hula Hoop. (6) Flexibility is seen when children move the body when playing Hula Hoop in the stomach. (7) Innovation is seen when children do variations of the new movement. (8) The stability of the weight is seen from report document of the weight and height of children in group B TK Bon Thorif which begins from March to July.

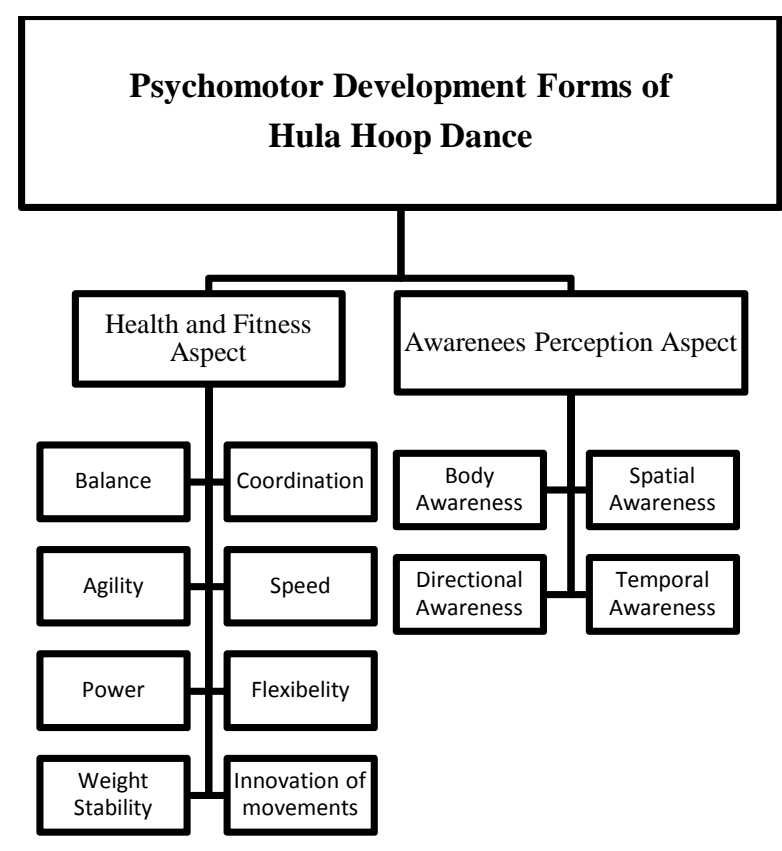

Figure. 1 The result of theme analysis. Psychomotor development forms of Hula Hoop Dance in Bon Thorif Kindergarten

Forms of psychomotor development in the aspects of perceptual motor include: (1) Body awareness is seen when children can name and feel the body heat, pulse and sweat before and after dancing the Hula Hoop. (2) Spatial awareness is seen when the child sets the distance with friends while adjusting the position to dance the Hula Hoop. (3) Directional awareness is seen when children move Hula Hoop to the front, right-left, up-down while performing heating up and cooling down according to the direction of teachers. (4) Temporal awareness is seen when the child moves when you hear the music and vice versa, and are able to distinguish the sound of the teacher, the environment, and music. 


\section{DISCUSSION}

Discussion of the result this research is divided into two aspects: health-fitness and awareness perception aspect.

\subsection{Health and Fitness}

The above findings are supported by the results of interviews of 1 to 4 with the principal and teachers. Here are excerpts of interview with one of the teachers that said "Free the child such as balancing the body either at rest or moving when dancing, coordinate eye movements, hands, feet, head, up to his body while dancing the Hula Hoop. Agility can be seen from parts of his body while moving quickly and accurately change the direction. Then the child's body flexibility can be seen when playing Hula Hoop around her waist, abdomen, arms, legs, thighs, neck. Speed in turning the Hula Hoop. Its power or endurance body associated with a strong force. "Here are excerpts of interview with the parents' feeling very happy to see Gendis dancing Hula Hoop. Hula Hoop activity is very nice to Gendis because it can offset the intake of food that he eats. Gendis get to eat too much, so by dancing Hula Hoop his weight becomes stable. It can be said to be balance, because if it is not matched with the movement, Gendis might be overweight."

To support observations and interviews above, there is a document supporting the stage of dancing Hula Hoop which is written for teachers as a guide in performing Hula Hoop Dance which is attached. Based on the findings in the field, it is proven that some theories support the above findings. Pica (2010:6) skills in combinations of three fundamental movements for the development of movement child individually and in groups. Associated with the Hula Hoop Dance, teachers also develop fundamental movement skills combination. Teachers develop children's skills in performing movement combination of locomotor, manipulative, and stability at the same time. Both are essential for development in early childhood. It is because when the child gets movement controls it will certainly affect positively to the mastery of fundamental movement skills of children. Likewise with Gallahue and Ozmun (2006:187) that divide three fundamental movements pattern classification include: locomotor, stability, and manipulative movement. The third movement patterns were developed separately first, after which it is combined between the movement and the movement of the other. The combination of basic movement more emphasis on the process and not the result of the combination, but the process when children do combined movements.

In the fitness aspect there are two parts of the movement: control and power production.

Movement control in children who were identified includes: balance and coordination. This is similar to that expressed by Gallahue and Donnelly (2003:187) there are factors such movement controls balance and coordination. Both are essential for development in early childhood. It is because when the child gets movement controls, it will certainly affect positively to the mastery of fundamental movement skills of children. Factors of production or labor force includes: speed, agility, and power. These factors are very important as the child is able to master movement and heading to the stage which is basically a special movement at the next phase of mastery of movement skills.

Sharkey and Gaskil (2007:147) mentions the balance is divided into two static and dynamic that occurs when a person moves. Reviewing the above opinion that describes the process of movement of the balance in children. It is inseparable from the teacher's role as motivator and facilitator in Hula Hoop Dance activities. Teachers motivate children to continue to make a move until they are skilled for dancing Hula Hoop. In addition, teachers also become a facilitator for children, one of them by playing music while dancing, giving children the opportunity to discover the balance movement.

McMurray (2002:9) includes motor coordination locomotor movement and motor coordination of eye and hand. Coordination is the basis and requirements for each moment of daily motor activity that is done. With the mastery of good coordination, it is certainly a positive impact on the continuity of the activity of movement every day, from waking up to going to sleep again. In relation to Hula Hoop dance, the coordination is done when children play with her Hula Hoop. It is the child doing with their hand-eye coordination with the movement when playing Hula Hoop. Later eye coordination and footwork is seen when a child is playing the Hula Hoop on foot. Coordination body rough in children involves fast body movement while performing a variety of fundamental movement skills. Associated with the Hula Hoop Dance activity coordination body can roughly be seen when the child jumps, move forward and backward, spinning, walking around, and more. Everything is closely related to the locomotor movement where movement is done when the body switches positions.

Gifford (2010:10) states that speed is the ability to move the body as quickly as possible. In connection with the Hula Hoop Dance activities, part of the body is like a hand and stomach. Both 
activities play Hula Hoop in both parts of the body develop well after the child skilfully turned the Hula Hoop. Followed by agility to change direction or position quickly.

Gifford (2010:10) states that agility is closely linked to the ability to balance the body to remain stable and not fall while doing the movement. Associated with a Hula Hoop Dance, it is seen when children play Hula Hoop both hands alternately premises without falling, this indicates the child's ability to change the direction of movement of a spinning Hula Hoop in the right hand and then move quickly to the left hand. Then, when children play Hula Hoop in the stomach or in the hand while doing leg variations accurately as jumping, it also showed his ability to change direction when jumping to the right of the da to the left quickly and did not fall while doing the movement.

Sharkey and Gaskil (2007:146) state that strength is the ability to perform maximum efforts in the shortest possible time. Observing second expert opinion above, the strength is the ability to perform maximum efforts in a move that could be affected by factors of power and speed. If combined with Hula Hoop Dance, the ability of children in dancing Hula Hoop without complaining certainly indicates that there is more that child labor had to do extra sessions while dancing the Hula Hoop.

Mayesky in Bursztyn (2012:199) argues that involvement of children towards innovation and discovery will have an impact in society. Further Mayesky declare innovation and invention arises from curiosity develops and the results of the expression of the children, and this curiosity will remain alive while children nurture their creativity as well. Consider the above passage of innovation is closely related to cognitive ability because of the innovations developed as a result of the creative thinking of children in creating a new movement with the idea. The results of these creative also in the form of movements that require control and production of energy to move so that the child can master the fundamental movement skills of a combination of movement. If connected with the activity of Hula Hoop, then shape the development of innovation, including the form development of the psychomotor domain. This is because innovation is more emphasis on practical skills or not thinking.

Gallahue (2013:3) states that joint flexibility is the ability of the various joints of the body to move through the various spheres of their gestures. In other words flexibility refers to also as joint flexibility when it is related to child's body movement with Hula Hoop dance, joint flexibility is actually contained in the body of the stomach, arms, and others.
Holthusen, at all (2010:1) state that Hula Hoop has become a sort of craze in making a person become healthy and fit. Hula Hoop is also regarded as a supporting activity of the form of whole body workout that can burn calories up to 600 calories per hour. Beside it is beneficial to the health and fitness of children it will also impact both on the child's ideal body proportion. Related to the shape of development of weight stability which is developed by the teacher on Hula Hoop Dance activities it intended that the child can maintain the stability of their weight and food intake to compensate for movement activity their children do. Of course, when children eat a lot and move on it will have an impact on a proportional body.

\subsection{Awareness Perception}

Based on the findings of the form of the development of psychomotor on aspects of the perception of movement comprising: Sensitivity to the body, space, direction and sound development of teachers in Hula Hoop dance activities intended that children are able to train their sensitivity to the body, space, direction and sound while moving Hula Hoop dance thus prevent children from mistakes and injuries. For that teachers can acts as a facilitator, motivator and mediator for children to develop a child's awareness perception of movement while doing the Hula Hoop Dance.

Gallahue (2013:268) states that the body's sensitivity is the ability to distinguish between the parts of the body and to gain a greater understanding of the nature of the body occurs in three areas. The first is knowledge of body parts which is children's ability to accurately look up on the body parts of themselves and others, the second is the knowledge of what to do to the body parts, the third is the knowledge of how to make body parts move efficiently. Of the three areas above, which is closely related to Hula Hoop dance which is part of the first and second, because the children are trained to demonstrate the sensitivity of her body as to point out the pulse accurately, children understand the parts of the body that indicate the body heat and indicates the sweat on his body, then the children are also taught about the function of the part, for example, just touching the body heat allows the child to know how fit his body to follow the movement of Hula Hoop Dance activity.

Gordon and Browne (2014:334) state that spatial awareness means a sense of sensitivity of the body and space to interact. And children will gain knowledge about what to do the body parts while moving. In connection with the Hula Hoop Dance, when children dance Hula Hoop the child should 
understand the body as it moved along with his friend, the child should be able to maintain or adjust the distance against a friend in front, left and right side, as well as behind as it moves. Actually, the body's sensitivity and the room is very related to one another because when the child moves, the sensitivity of the body which will also contribute significantly to the effectiveness in regulating body movement.

Furthermore, Gordon and Browne (2014:334) states that before the age of six to eight years, children have developed spatial ability which makes them more abstract to distinguish between left and right on their own body and the other body, meaning in this case the body of the teacher who was cited movement in the warming up, whilst activity of Hula Hoop, and cooling down. In particular, sensitivity of the body to the direction refers to the left and right, top and bottom, front and back, top and bottom. Child can follow the movement of the teacher by himself. For the teachers who supervised or exemplifies child Hula Hoop Dance in movement when he was in front of the children should perform mirroring movements on the right and left. For example, the position of the teachers is in front of children, and teachers provide instruction to move the Hula Hoop to the right, then the movement of teachers should be toward the left.

Gordon and Browne (2014:345) state that temporal awareness to sound is the child inner ability. It can also be called as a structure that allows the child to coordinate parts of the body. Dance to the rhythm, speed up and slow down, and develop the skills of this kind. It is also a great way to help children learn to predict the time. Children become more capable of knowing when the body should start dancing and when to stop moving his body to dance the Hula Hoop. In addition, children become more able to distinguish sounds while dancing the Hula Hoop. Starting from the sound of music Hula Hoop, voice instruction teacher, and sound environment.

\section{CONCLUSIONS}

Early Childhood Education Bon Thorif carries out the development of psychomotor activity Hula Hoop Dance. Forms of psychomotor development that is developed at Bon Thorif Kindergarten include psychomotor development in health fitness, and children's awareness perception. Psychomotor development in the implementation of activities Hula Hoop Dance, needing more if the child's body that emphasizes the aspects like movement control in moving. The perceptual motor that will have an impact on children's health and fitness. The shape of the main psychomotor development of the fundamental movement skills development include: stability, locomotor, and manipulative movement skills. Found more forms of psychomotor development is that in the health and fitness aspects include: balance, coordination, agility, speed, power, flexibility, innovation, and weight stability. Further forms of psychomotor development in the awareness perception include: the body's awareness, spatial awareness, directional awareness, and temporal awareness.

Based on the results of the analysis of the research results, it can be formulated the theory of substantive as follows: "If the child has shown if the body in moving the implementation of the activities Dancing Hula Hoop characterized by: skill combination of fundamental movement skills (stability, locomotor, manipulative), balance, coordination, agility, speed, strength, flexibility, innovation, stable body weight, body awareness, the spatial awareness, directional awareness, and temporal awareness, then the teacher has developed psychomotor skills of children both in terms of the combination of fundamental movement skills, health and fitness as well as the awareness perception."

\section{REFERENCES}

Anderson, Lorin W. \& Sid F. Bourke. (2000). Assessing Affective Characteristics in the Schools Second Edition. London: Routledge.

Astono, Sigit, dkk. (2007). Apresiasi Seni: Seni Tari dan Seni Musik 2. Jakarta: Yudisthira,

Bursztyn, Carol Korn. (2012). Young Children and The Arts: Nurturing Imagination and Creativity. USA: Information Age Publishing, Inc.

Creswell, John W. (2007). Qualitative Inquiry and Research Design: Choosing Among Five Approches. New delhi: Sage Publication.

Gallahue, David. (2006) "Chapter 3: Motor Development: A Theoritical Model. Retrived October 27, 2013 from http://highered.mcgrawhill.com/sites/dl/free/ 0073376507/934254/Chapter3.pdf.

Gallahue, David L \& Frances Cleland Donnelly. (2003). Developmental Phisical Education for All Children. China: Human Kinetics.

Gallahue, David L dan John C. Ozmun. (2006). Understanding Motor Development Infants, Children, Adolescents, Adults: Six Edition. New York: McGraw Hill.

Gifford, Clive. (2010). Healty Lifestyle Sporting Activities. Lodon: Evan Brothers Limited. 
Goodway, Jacqueline D dan Leah E. Robinson. (2006). Skiping Toward an Active Start: Promoting Physical Activity in Preschoolers. Retrivied November 15, 2013 from http://www.naeyc.org/files/naeyc/SKIPing_Go odwayBTJ.pdf.

Gordon, Ann Miles \& Kathryn Williams Browne. (2014). Beginning and Beyond: Foundations In Early Childhood Education, Ninth Edition. USA: Wadsworth.

Holthusen, at all. (2010). Hooping-Efective Workout or Child's Play?. Retrivied June 29, 2014 from http://www.acefitness.org/ certifiednewsarticle/1094/ace-sponsoredresearch-hooping-effective-workout.

Lemos, Anderson. G, Eric L. Avigo, Jose A. Barela. (2012). Physical Education in Kindergarten Promotes Fundamental Motor Skill

Development. Scientific Research, 21. Retrivied October 26, 2013 from http://www.SciRP.org/journal/ape.

Lloyd, Rebecca J., et. all. (2011). Hula-Hooping for Health \& Happiness. Research, Retrivied November 3, 2013, from http://www.developingaglobal perspective.ca /wpcontent/assets/unitplans/gr2/Hula_Hoopig.p df.

McMurray, Robert. (2002). Coordination a New Approach to Soccer Coaching. UK: Meyer \& Meyer Sport.

Miles, M.B dan Huberman. (1984). Data Analysis. USA: Sage Publication.

Moleong, Lexy. J. (2005). Metodologi Penelitian Kualitatif. Bandung: Remaja Rosdakarya.

NASPE (National Asociation Sport and Physical Education). (2008). Appropriate Instructional Practice in Movement Programs For Children Ages 3-5. Retrivied December 3, 2013 from http://www.cahperd.org/cms/assets/documents/ ToolKit/NASPE_ApprroPrac/5286668190.chil dren3to5approprac.pdf.

Peraturan Menteri Pendidikan Nasional Republik indonesia Nomor 58 Tahun 2009 tentang Standar pendidikan Anak Usia Dini. Jakarta: Departemen Pendidikan Nasional.

Pica, Rea. (2000). Experience in Movementwith Music, Activities, \& Theory 2nd Edition. Canada: Delmar Staff. (2010). Experience in Movement and Music Birth to Age 8 Fourth Edition. USA: Wadsworth.

Saracho, Olivia. N \& Bernard Spodek. (2013). Handbook of Research on The Education of Young Children:The Dance of Learning Study. New York: Routledge.
Sharkey, Brian J dan Steve E. Gaskill. (2007). Fitness \& Health Sixth Edition. Hong Kong: Human Kinetics,

Soedarsono. (1992). Pengantar Apresiasi Seni. Jakarta: Balai Pustaka.

Spradley, James P. (1980). Partcipant Observation. New york: Holt, Rinehart and Wiston.

Wolf, Elizabeth. (2004). Creating the Enviroment for Movement, http://www.naeyc.org/files/naeyc/Creating the Environment_for_Movement. pdf.

Woodside, Arch G. (2010). Case Study Research: Theory, Methods, Practice. USA: Emerald Group Publishing Limited. 